\title{
Patterns of alignment in verb agreement
}

Bickel, Balthasar ; Iemmolo, Giorgio ; Zakharko, Taras ; Witzlack-Makarevich, Alena

DOI: https://doi.org/10.1515/9783110331127.15

Posted at the Zurich Open Repository and Archive, University of Zurich

ZORA URL: https://doi.org/10.5167/uzh-79050

Book Section

Published Version

Originally published at:

Bickel, Balthasar; Iemmolo, Giorgio; Zakharko, Taras; Witzlack-Makarevich, Alena (2013). Patterns of alignment in verb agreement. In: Bakker, Dik; Haspelmath, Martin. Languages across boundaries : Studies in memory of Anna Siewierska. Berlin: De Gruyter Mouton, 15-36.

DOI: https://doi.org/10.1515/9783110331127.15 


\section{Balthasar Bickel, Giorgio lemmolo, Taras Zakharko, and Alena Witzlack-Makarevich \\ Patterns of alignment in verb agreement ${ }^{1}$}

\section{Siewierska’s Problem}

A highly productive inquiry in typology concerns the alignment of argument roles, especially the identical vs. different treatment of the three core roles S, A, and P by the rules of case assignment and agreement marking. With regard to case marking, determining alignment is straightforward: one can simply check which argumental NPs are assigned the same case markers. With regard to agreement, the issue is more complex. Whereas argumental NPs exist independently of case marking, agreement consist of two components: (i) whether or not it exists (i.e. whether certain argument features like person, number of gender, show up at all in the verb morphology), and (ii) if agreement exists, how its markers align roles. In many cases, the answers to these question are still straightforward and one can easily observe that the agreement markers of, e.g., Latin show accusative alignment.

However, when expanding the typological scope, one often runs into what we call here "Siewierska's Problem": argument marking in agreement is often complex and does not allow simple answers. As a matter of fact, the analysis of an agreement system as being primarily ergative, accusative or neutral heavily depends on which criteria one employs. As Siewierska (2003) notes in her seminal article on the determination of the alignment of agreement in ditransitive constructions, in some instances the consideration of different criteria gives rise to conflicting classifications, i.e. the criteria may not converge in identifying a unique alignment type. Siewierska (2003: 342) considers the following four criteria that apply to the determination the alignment of agreement: ${ }^{2}$

1 Earlier versions of this article were presented at the Anna Siewierska Memorial Workshop in Leipzig, April 27, 2012, and at the conference "Syntax of the World's Languages IV" in Dubrovnik, October 1-4, 2012. We thank the audiences for helpful comments and questions. We are also grateful for very useful comments and suggestions on a first drft by Dik Bakker and Martin Haspelmath. Author contributions: B.B., G.I. and A.W.-M. conceived and designed the study and all contributed to the writing. B.B. conducted the statistical analysis. All authors were involved in discussion and interpretation of the results. G.I. and A.W.-M. contributed to data analysis and coded agreement data. T.Z. did most of the data extraction and aggregation work. We thank Lennart Bierkandt and Kevin Bätscher for help in data collection and encoding

2 A further criterion, not considered by Siewierska (2003), concerns the host(s) of agreement marker(s), i.e. auxiliaries, lexical verbs, etc. We will not consider this criterion here either. 
1. Trigger Potential: which argument(s) do and which do not trigger agreement marking (i.e. does agreement exist at all)?

2. Form: which argument(s) are covered by the markers with the same phonological form?

3. Position: which arguments trigger agreement in the same position relative to the verbal stem and/or relative to each other (e.g. pre, post, etc.)?

4. Conditions: which arguments trigger agreement under the same condition?

As observed by Siewierska, often these four factors converge in establishing an overall agreement pattern, as, e.g., in German in (1) below, where all the criteria listed above give a consistent alignment pattern. In terms of Trigger Potential, German displays accusative alignment: only $S$ and $A$ trigger agreement. When we take into consideration the Form and Position criteria, we see that they comply with the Trigger Potential characterization: with respect to the Form criterion, the system is consistently accusative, with $\mathrm{S}$ and A marked differently from $\mathrm{P}$, since $\mathrm{P}$ is never overtly marked in German verb agreement. ${ }^{3}$ Likewise, with regard to the Position criterion, we have again $\mathrm{S}=\mathrm{A} \neq \mathrm{P}$, since agreement is realized by means of an overt suffix only for $\mathrm{S}$ and $\mathrm{A}$.

(1) German
a. Ich schlaf-e.
1sG.NOM sleep-1sG.s/A
'I sleep.'

b. $D u \quad$ schläf-st.

2sG.Nom sleep-2sG.s/A

'You sleep.'

c. $E r$

schläf-t.

3sG.M.Nom sleep-3sG.s/A

'He sleeps.

d. Ich seh-e sie.

1sg.nom see-1sG.S/A 3sG.F.ACC

'I see her.'

3 Here and in the remainder of the paper, we simplify. We only consider default lexical classes and do not discuss deviating valency classes such as experiencer verbs. Also see below on this point. 

e. $D u$ sieh-st mich.
2sG.NOM see-2sG.s/A 1sG.ACC
'You see me.'
f. $E r$ sieh-t dich.
3SG.M.NOM see-3SG.S/A 2sG.ACC
'He sees you.'

However, in many other languages these criteria diverge in defining the alignment of agreement, thus giving rise to discrepancies. The situation can be illustrated with English: most English verbs in the present indicative are marked with the suffix $-s$ when the subject is third person singular and are unmarked otherwise, as in (2):
a. They like sailing.
b. He like-s sailing.

With respect to the Trigger Potential criterion, the English present indicative agreement system can be characterized as exhibiting accusative alignment. However, when the distribution of zero versus overt agreement markers is taken into account (i.e. the Form criterion), S/A is marked differently from $\mathrm{P}$ only in the third person singular, whereas the alignment is neutral $(\mathrm{S}=\mathrm{A}=\mathrm{P})$ in the rest of the paradigm, as none of the argument roles triggers an overt agreement marker.

More complex discrepancies arise in systems with multiple markers per argument. An illustration of such a system comes from the imperfective agreement paradigm found in Tirmaga (Surmic; Bryant 1999), which has three slots of agreement marking: one prefix and two suffix slots. Table 1 shows the paradigms separately for each of the three roles $\mathrm{S}, \mathrm{A}$, and $\mathrm{P}$.

Table 1. Agreement paradigms for S, A, and P in the Tirmaga Imperfective aspect

\begin{tabular}{l|cll|lll|lll}
\hline Person & pf & $\mathbf{s f 1}$ & $\mathbf{s f 2}$ & $\mathbf{p f}$ & $\mathbf{s f 1}$ & $\mathbf{s f 2}$ & $\mathbf{p f}$ & $\mathbf{s f 1}$ & $\mathbf{s f 2}$ \\
\hline $1 \mathrm{~s}$ & $k-$ & - & $-i$ & $k-$ & - & $-i$ & - & $-a \rho$ & - \\
$1 \mathrm{pi}$ & $k-$ & - & - & $k-$ & - & - & - & $-e y$ & - \\
$1 \mathrm{pe}$ & $k-$ & - & $-(G) o$ & $k-$ & - & $-(G) o$ & - & $-e y$ & - \\
$2 \mathrm{~s}$ & - & - & $-i$ & - & - & $-i$ & - & $-a n$ & - \\
$2 \mathrm{p}$ & - & - & $-(G) o$ & - & - & $-(G) o$ & - & $-o \eta$ & - \\
$3 \mathrm{~s}$ & - & - & - & - & - & - & - & - & - \\
$3 p$ & - & - & $-(G) \varepsilon$ & - & - & $-(G) \varepsilon$ & - & - & - \\
\hline & & $\mathbf{S}$ & & & $\mathbf{A}$ & & & $\mathbf{P}$ & \\
\hline
\end{tabular}


The application of the criteria to the Tirmaga paradigm provides conflicting evidence on the alignment pattern. When one considers the Trigger Potential criterion, the resulting alignment is neutral, since all the three roles $\mathrm{S}, \mathrm{A}$, and $\mathrm{P}$ display some kind of agreement marking, at least in part of the system. With regard to the Position criterion, Tirmaga shows accusative alignment, since $S$ and A are marked in the prefix ('pf') slot and in the second suffix ('sf2') slot respectively, as opposed to the markers for P, which occupy the first suffix ('sf1') slot. Under the Form criterion, finally, one considers the phonological shape of individual markers and asks which argument roles are marked by identical vs. distinct markers. The Form criterion does not establish a unique alignment pattern in the Tirmaga paradigm: the prefix position shows accusative alignment in the first person ( $\mathrm{S}$ and $\mathrm{A}$ is marked with $k$ - and thus differently from $\mathrm{P}$ ), whereas other persons have zero exponence which covers all roles alike, thereby constituting neutral alignment. In the first suffix slot non-third person argument is accusatively aligned due to the suffixes -an, -ey, -oy, whereas the absence of overt markers for the third person arguments establishes neutral alignment. In the final suffix slot, there is again a number of markers $(-i,-(G) o,-(G) \varepsilon)$ which establish the accusative alignment, whereas arguments of those referential categories which have zero exponents for all three argument roles (i.e. the first person plural inclusive and the third person singular) align neutrally. The alignment patterns established on the basis of these three criteria and the observed discrepancies are summarized in (3).

(3) Tirmaga agreement alignment

a. Trigger Potential: $\mathrm{S}=\mathrm{A}=\mathrm{P}$

b. Form: $\mathrm{S}=\mathrm{A} \neq \mathrm{P}, \mathrm{S}=\mathrm{A}=\mathrm{P}$

c. Position: $\mathrm{S}=\mathrm{A} \neq \mathrm{P}$

With the exception of Siewierska (2003), discrepancies like these have received little attention in the typological literature or in the description of individual languages. This article intends to explore the distribution and influence of such discrepancies in the determination of the alignment in agreement systems, focusing specifically on discrepancies between alignments in terms of Trigger Potentials and alignments in terms of Form. We explore two research questions:

1. How frequent and how strong are these discrepancies cross-linguistically?

2. Do these discrepancies have an impact on our generalizations about the distribution of alignment systems?

We begin by describing the database used for this study and then address these questions in turn. 


\section{Data, analysis and coding methods}

We surveyed 260 languages and coded their agreement systems for alignment patterns as part of the AUTOTYP database of grammatical relations. ${ }^{4}$

Unlike Siewierska (2003), whose focus was on person agreement only, we also considered instances of gender, number and honorificity agreement. To keep our dataset manageable in size, however, we treated gender-differentiating agreement markers as if they were just one marker, i.e. we did not track the difference between for example third person masculine vs. feminine agreement, but simply third person gender agreement. We considered a particular person-number-gender combination as overtly marked if it is overtly marked for at least one gender.

Also departing from Siewierska, we only looked at grammatical agreement in the sense of Bickel \& Nichols (2007), i.e. we only coded verbal markers of argument properties that can in principle co-occur with a coreferential noun phrase in the same clause (regardless of whether this co-occurrence is frequent or rare in discourse). Grammatical agreement in this sense corresponds to what Siewierska (2004) treats as the union of syntactic and ambiguous agreement. Cliticized or incorporated pronouns that cannot co-occur with co-referential noun phrases were not analyzed as instances of agreement.

For coding alignments, we considered only the coding of S, A, and P argument roles and excluded arguments of ditransitive verbs from our present purview. $\mathrm{S}, \mathrm{A}$, and $\mathrm{P}$ are defined by numerical valency and semantic entailment properties of lexical predicates, following earlier proposals of ours (Bickel \& Nichols 2009, Bickel et al. 2010, Bickel 2011a, Witzlack-Makarevich 2011). We furthermore limited our attention to lexical predicates that qualify as open, default classes of their language and excluded predicates with non-canonical agreement patterns, other special behavior, or lexical constraints of any kind.

We analyzed the alignment of agreement systems under the two criteria of (i) Trigger Potential, i.e. which argument(s) trigger(s) agreement; and (ii) identity of Morphological Marking, which implies identity of both phonological form and morphological slot. ${ }^{5}$ The formulation of the second criterion is similar to Siewierska's Form and Position criteria but departs from her original proposal in so far as we took into consideration individual slots in which given phonological forms appear in the string of morphemes, rather than a binary prefix vs. suffix distinction.

4 The dataset used in this study is available for download at http://www.spw.uzh.ch/autotyp/ available.html

5 An alternative approach would be to take into account just phonological properties, abstracted, if possible, across positions. While possible and interesting, we leave the exploration of this alternative for another occasion. 
The two criteria basically equate the Trigger Potential with syntax and Morphological Marking with morphology, allowing us to frame the question in terms of possible discrepancies between how argument roles are aligned in agreement syntax as opposed to agreement morphology. Agreement syntax in this sense refers to whether or not the verb - or more generally, any predicate complex that heads a clause - registers features contained in S, A or P and therefore systematically interacts with these arguments. If a specific argument does not trigger agreement at all (e.g., P arguments in German), this means that the verb does not interact with this argument at all in the syntax. Such questions of verb-argument interaction are fundamental for the organization of syntax, typically requiring specific modeling in formal theories.

This conceptualization of Trigger Potentials and Morphological Marking as two dimensions of agreement does not match traditional grammar, where they are not kept separate. For data like those from Tirmaga in Table 1, one would traditionally focus on the form and position of markers and argue that the paradigms show (mostly) accusative alignment. The fact that all three arguments behave alike in triggering agreement would not be considered an interesting fact. For other languages, however, traditional grammar would focus precisely on triggering behavior and not consider form and position criteria. For German for example, one would traditionally say that only S and A arguments trigger agreement; one would not say that German is accusatively aligned because S and A have overt agreement markers whereas P shows zero markers. Applying different criteria in Tirmaga and in German is typologically inconsistent, as Siewierska has noted.

Furthermore, it is essential to keep apart cases (i) where an argument has a Trigger Potential but the morphology happens to be zero in a specific category (such as third person singular in Tirmaga) and (ii) where an argument never triggers agreement (like German P arguments). In type (i), the grammar of the verb has to check for the presence of specific features in all arguments, and as a result, the verb enters a specific morphosyntactic relationship with all arguments.

The same morphosyntactic relationship does not exist between the verb morphology and arguments that never trigger verb agreement, i.e. in type (ii). In other words, there is a fundamental difference between accusative alignment in a language like Tirmaga and accusative alignment in a language like German, and this difference can only be captured by following Siewierska's innovation and consider Trigger Potentials independently of Morphological Marking.

Trigger Potential is a notion that is uniquely tied to agreement: it is only for agreement that it makes sense to ask whether there exists a specific syntactic relationship between the verb and features of a specific set of arguments. There is no equivalent of this in case assignment: the syntactic relationship that is marked 
by case exists independently of case assignment, as argumental NPs always bear a syntactic relationship to the predicate since they are assigned a semantic role by it. The relationship is not established by the presence of case morphology, and so one would not say that $\mathrm{P}$ arguments in, say, Thai bear no syntactic relation to the verb just because there is no case marking. Instead, case morphology can be said to mark the existing relationship. As a result of this, the absence of case morphology is equivalent to zero marking and not to the absence of syntactic relationships. Therefore, in contrast to agreement marking, case marking can be fully determined by considering Morphological Marking; the Trigger Potential has no role to play here.

When looking at Morphological Marking in agreement, we considered which roles trigger overt agreement morphology per referential category (i.e. per every person/number combination) in every relevant morphological slot in the predicate. Consider the data in (4) from the Uto-Aztecan language Pipil:

(4) Pipil (Uto-Aztecan; Campbell 1985)
a. ni-panu
1sG.s/A-pass
'I pass'
b. ni-mits-ita-k
1SG.S/A-2SG.P-see-PST
'I saw you'
c. ti-nech-ita-k
2SG.S/A-1SG.P-see-PST
'You saw me'
d. panu
[3s/A-]pass
'he passes'
e. ki-neki
[3s/A-]3sG.P-want
'he wants it'
f. ni-k-neki
1SG.S/A-3SG.P-want
'I want it'

If we consider the morphological realization of agreement in the first prefix slot in Pipil, we observe a $\mathrm{S}=\mathrm{A} \neq \mathrm{P}$ alignment for the first person singular: there is $n i$ - 
'1sS/A' for S in (4a) and for A in (4b), but zero exponence for the first person singular P role in this slot, as (4c) shows; first person singular P is instead marked in the second slot (-ne in (4c)). The situation is identical for the first person plural and for the second person. However, when we consider the morphological marking of the third person within the first prefix slot, we observe that three roles behave alike $(\mathrm{S}=\mathrm{A}=\mathrm{P})$, in that none of them shows up with an overt morphological trace in this slot (be it a dedicated marker or a portemanteau affix, cf. (4d-f)). The markers in the first prefix slot here only register first person (4f)). This is different for the second prefix position, filled by mits- in (4b), and ki- in (4e) and (4f). Here one obtains $\mathrm{S}=\mathrm{A} \neq \mathrm{P}$ alignment, since the markers that appear in this slot encode the $\mathrm{P}$ argument, as opposed to $\mathrm{S}$ and $\mathrm{A}$, which leave no overt morphological trace in this slot.

The situation is again different in the suffix position. Here we have neutral alignment for singular arguments, since this category never results in overt morphology across all persons. For plural arguments, however, there is an opposition between overt marking of S and A (cf. - $t$ in (5a) and (5b)) vs. no marking for P (5c), again across all persons:

Pipil (Uto-Aztecan; Campbell 1985)

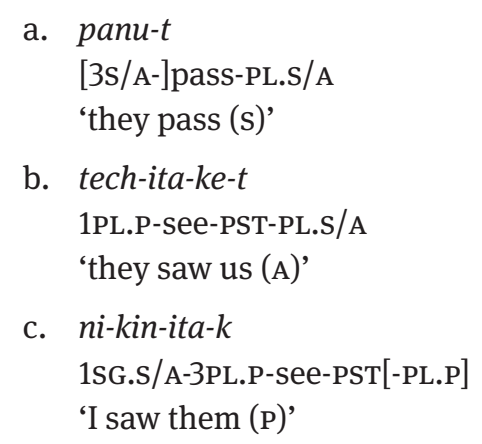

The example of Pipil also shows that alignment can differ across referential categories. In the first prefix we get $\mathrm{S}=\mathrm{A}=\mathrm{P}$ for the third person and $\mathrm{S}=\mathrm{A} \neq \mathrm{P}$ elsewhere; in the suffix slot, we get $\mathrm{S}=\mathrm{A}=\mathrm{P}$ in the singular and $\mathrm{S}=\mathrm{A} \neq \mathrm{P}$ in the plural. The second prefix slot, by contrast, shows consistent $\mathrm{S}=\mathrm{A} \neq \mathrm{P}$ alignment for all referential categories.

In case a language has multiple allomorphs of agreement markers (e.g. conditioned by inflectional classes), we proceeded as follows: morphologically overt allomorphs were encoded as the same marker for the present purposes. If one of the allomorphs has zero exponence, we considered the size and productivity of individual inflectional classes. Only the major pattern of marking - either in 
terms of the number of inflectional classes or, where the information is available, in terms of the class size - was considered. For instance, for Latvian three conjugation classes with several subclasses are differentiated. Class II (also referred to as "long") and the overwhelming majority of verbs in Class I (called "short") have zero exponence for the second person singular present, whereas the verbs of Class III ("mixed") use the suffix $-i$ in this context. As the most productive and numerous class is Class II, the exemplar paradigm selected for Latvian has no overt marker in the second person singular present (cf. Holst 2001, Mathiassen 1997, Nau 1998).

For easy data entry, we only coded overt markers. The distribution and semantics of zero exponents was then automatically inferred with the help of an ancillary database that tracks all referential features that an agreement system is sensitive to. Thus, in the case of the Pipil first prefix slot, zero exponence of S/A agreement for third person forms is not explicitly coded in the database, but it can be inferred from the list of the referential types of Pipil which includes three persons and two numbers. The same holds for the singular arguments in the suffix slot. ${ }^{6}$ Since agreement systems sometimes undergo splits conditioned by temporal-aspectual properties of the clause (e.g. past vs. non-past, perfective vs. imperfective) we tracked the effects of these conditions in the database and considered the affected alignment patterns as individual datapoints. We refer to these patterns as constituting agreement 'systems' within a language in the following. The database thus contains a total of 289 systems from 260 languages.

\section{Does it make a difference?}

There are many languages where the alignment of Trigger Potentials deviates from the alignment of Morphological Marking. The extent of such discrepancies can be quantified by counting how often Morphological Marking shows alignment that is identical to the alignment of the Trigger Potential. In the English present tense, for example, one marker $(-s)$ differs and one marker (zero) is identical with the alignment of the Trigger Potential (which is $S=A \neq P$ ), resulting in an identical alignment proportion of .5 for this system. The histogram in Figure 1 shows the frequency of identical alignment proportions binned into ten intervals running from [0,.1] to [.9,1]. The rightmost interval consists almost completely of systems with no discrepancy at all (111 systems with an identical

6 All data processing, analysis and visualization was done in R (R Development Core Team 2012), with the added packages lattice (Sarkar 2010) and vcd (Meyer et al. 2009). 
alignment proportion of 1 , compared to 2 systems with a proportion between .9 and 1); the leftmost interval contains 19 systems with no identical alignment at all and 46 systems with identical alignment proportions greater than 0 and smaller or equal to .1 .

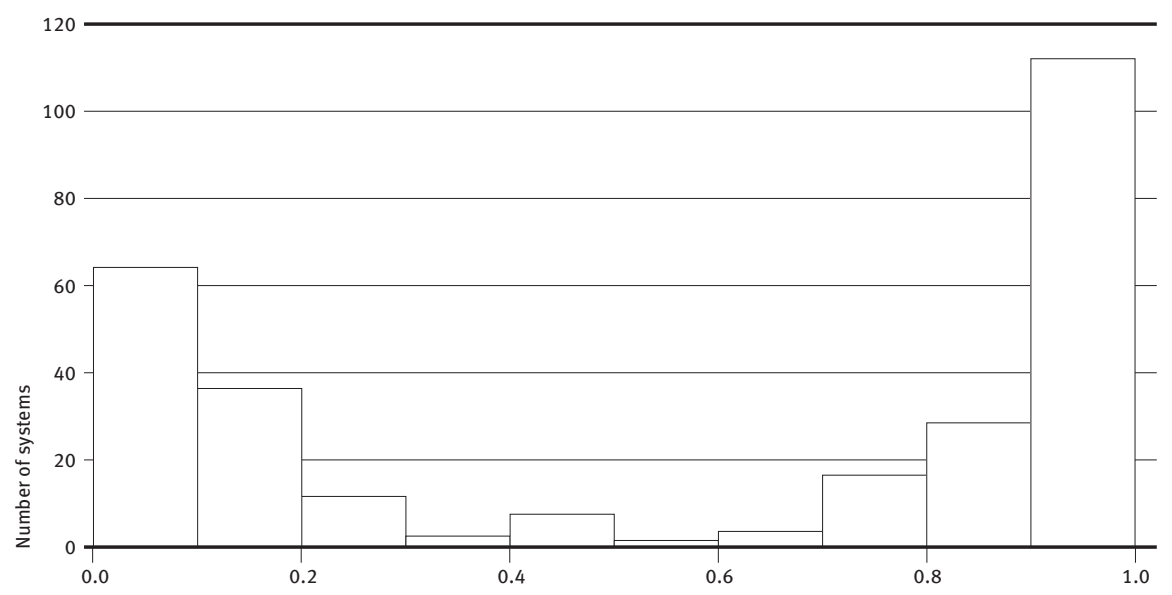

Figure 1. Histogram of the proportions of identical alignment between agreement morphology and trigger potentials in each system $(N=289)$.

In total, almost two thirds $(N=178)$ of the 289 systems in our database show at least some kind of discrepancy between alignments in terms of Trigger Potentials and alignments in terms of Morphological Marking. The histogram furthermore shows that discrepancies tend to be severe: $43 \%(N=125)$ show an identical alignment value below (or equal to) .5. These findings suggest that Siewierska's Problem is a serious one. It is imperative that typologies of alignment in agreement be clear on whether they refer to trigger potential or to agreement morphology and apply criteria consistently across languages. The two ways of looking at alignment differ substantially. While this is an important insight with many practical consequences for typology's day-to-day business, the theoretically more pressing question concerns the source and consequences of such discrepancies between syntax and morphology. We take up this issue in the following. 


\section{Sources of the discrepancies}

Two causes of discrepancies are trivial. First, if a referential type, e.g. third person singular, is always zero-marked (i.e. in any role) in a particular slot, its alignment is neutral, while overt markers can be distributed both according to neutral as well as according to any other alignment pattern. Second, tripartite alignment $(\mathrm{S} \neq \mathrm{A} \neq \mathrm{P})$ is logically possible only with Morphological Marking. Trigger Potentials can never have this type of alignment: if all roles trigger agreement this leads to neutral $(\mathrm{S}=\mathrm{A}=\mathrm{P})$ alignment, no matter how diverse the morphological shapes and positions may be; if only a subset triggers agreement, this leads to accusative $(\mathrm{S}=\mathrm{A} \neq \mathrm{P})$, ergative $(\mathrm{S}=\mathrm{P} \neq \mathrm{A})$ or horizontal $(\mathrm{S} \neq \mathrm{A}=\mathrm{P})$ agreement, again regardless of the morphological structure. This situation can be illustrated with the morphology of second person agreement in the Mayan language Ch'orti':

(6) Ch’orti' (Mayan; Quizar 1994)
a. i-wayan.
2sG.S-sleep
'you sleep (s)'
b. a-ira-en.
2sG.A-see-1SG.P
'you see me (a)'
c. in-ira-et.
1SG.A-see-2sG.P
'I see you (P)'

In the incompletive aspect there are two dedicated markers for the second person singular S (6a) and A arguments (6b). The P argument is not marked with a prefix, but with a suffix instead (6c). Thus, although the individual markers are different for the three argument roles S, A, and P, in terms of Trigger Potential the alignment is neutral, since all three argument roles equally trigger agreement.

Excluding all instances of zero exponence and of tripartite alignment in morphology brings down the proportion of systems with at least one discrepancy to 122 (42\%) out of 289 systems (from 178 or 62\%, cf. above). These remaining discrepancies are empirical observations, and not logically derivable from how alignment is defined. In other words, it could well be the case that languages would tend to favor similar alignments in the morphology as in the syntax, perhaps in response to iconicity principles. In that case, we would expect, for example, that neutral alignment in the syntax would tend to go together with neutral alignment in the morphology, so that we would find neutral markers in most morphological 
slots. Systems like this are apparently rare. What comes closest corresponds to what is sometimes called hierarchical agreement. A case in point is agreement prefixes in Plains Cree. Here, categories like second person trigger agreement in all three roles, and these roles receive exactly the same morphological marking (the prefix $k i$-):

(7) Plains Cree (Algonquian; Dahlstrom 1991)
a. ki-pimipahtā-n.
2-run-sG.s/A/P
'you (sG) run (s)'
b. ki-pēhtaw-i-n.
2-hear-2>1-SG.S/A/P
'you (SG) hear me (A)'
c. ki-pēhtaw-iti-n.
2-hear-1>2-SG.S/A/P
'I hear you (SG) (PL.P)'

But this seems to be very strongly disfavored worldwide and markers tend to differentiate roles, leading thus to discrepancies.

Discrepancies can arise independently in every slot of the agreement morphology and in every referential category: while in Cree, the alignment of the prefix slot is identical to the alignment of the Trigger Potential for the first and second person, the suffixes show various discrepancies. Consider, for example, the distribution of the second person plural suffix -nāwāw in one of the suffix slots (suffix slot 5):
a. ki-pimipahtā-nāwāw.
2-run-2PL
'you (PL) run (s)'
b. ki-wāpam-i-nān.
2-hear-2>1-1PL
'you (PL) see us (A)'
2-hear-1>2-2PL
'I see you (PL) (P)'
c. ki-wāpam-iti-nāwāw.

Whereas the $\mathrm{S}$ and $\mathrm{P}$ arguments of this referential type are marked with -nāwa $w$, as in (8a) and (8c), the A argument of the same referential type is not marked in 
this slot; instead we find a first person suffix -nān (8b). This results in ergative alignment. ${ }^{7}$

In general, each agreement category in each slot allows for maximally four types of how overt morphology can align roles $(S=A=P, S=A \neq P, S \neq A=P, S=P \neq A)$ if we exclude tripartite alignment (following the reasoning above). Therefore, the range of logically possible opportunities for discrepancies rises with the number of agreement categories and agreement slots. For instance, Jero (Opgenort 2005) has 11 referential categories for the $S$ argument (three person categories, three number categories and an inclusive vs. exclusive distinction in the first person of both dual and plural). Each of the marking of the A argument of these 11 types can be conditioned by the $\mathrm{P}$ arguments which again are of these 11 types (e.g. A of the first person singular when acting on the second person singular P, A of the first person singular when acting on the second person plural P, etc.). In the same fashion, the marking of the $\mathrm{P}$ argument across all 11 referential types varies with respect to the A argument and its referential types. To calculate alignment we take an $\mathrm{S}$ argument of a particular referential type and compare it with the A argument of the same referential type under one of the 11 conditions and with the $\mathrm{P}$ argument of the same referential type under one of the 11 conditions (Witzlack-Makarevich 2011, Witzlack-Makarevich et al. 2011). This results in $11^{3}$ alignment statements per agreement slot. Jero has 3 slots relevant for agreement and the number of alignment statements for each of them is theoretically $11^{3}$, that is, $11^{3} \times 3=3993$ alignment statements in total. The actual number of alignment statements is, however, somewhat lower than this amount of combinatorial possibilities, as particular referential categories or referential category combinations are non-existent or belong to a different (e.g. reflexive) paradigm. Nevertheless, there is still a very large space of opportunity for discrepancies, easily extending into several thousands when there are many categories and a complex system of morphological slots.

Interestingly, languages seem to exploit these possibilities to a substantial extent: Figure 2 plots the proportion of discrepancies, i.e. alignment statements that differ between Morphological Marking and Trigger Potential, per system against the number of category/slot combinations that are distinguished by that system. The data are limited to nontrivial cases of non-identical alignments, i.e. following the reasoning above, we consider here only overt morphology and exclude tripartite alignment. ${ }^{8}$ The plot suggests that the opportunity space

7 See Witzlack-Makarevich et al. (2011) on deriving basic alignment types from systems with hierarchical and coargument conditioned systems of alignment.

8 Note that a language like English counts as having 1 agreement category in the non-past (third person singular), i.e. we counted the number of overtly marked categories, not the number of feature values in oppositions. 
for discrepancies becomes heavily, and often fully, exploited with systems that contain more than 6 categories (67\% discrepancies with 7 categories in 6 systems, $34 \%$ with 8 categories in 17 systems, $88 \%$ with 9 categories in 8 systems etc.). Systems with fewer categories tend to show alignments that match the alignment of agreement trigger potentials either completely (displayed in the graph as thin horizontal lines at $0 \%$ with systems of $1,2,4$ or 5 categories) or to a large extent (12.5\% discrepancies with 3 categories in 8 systems, 14\% with 6 categories in 14 systems).

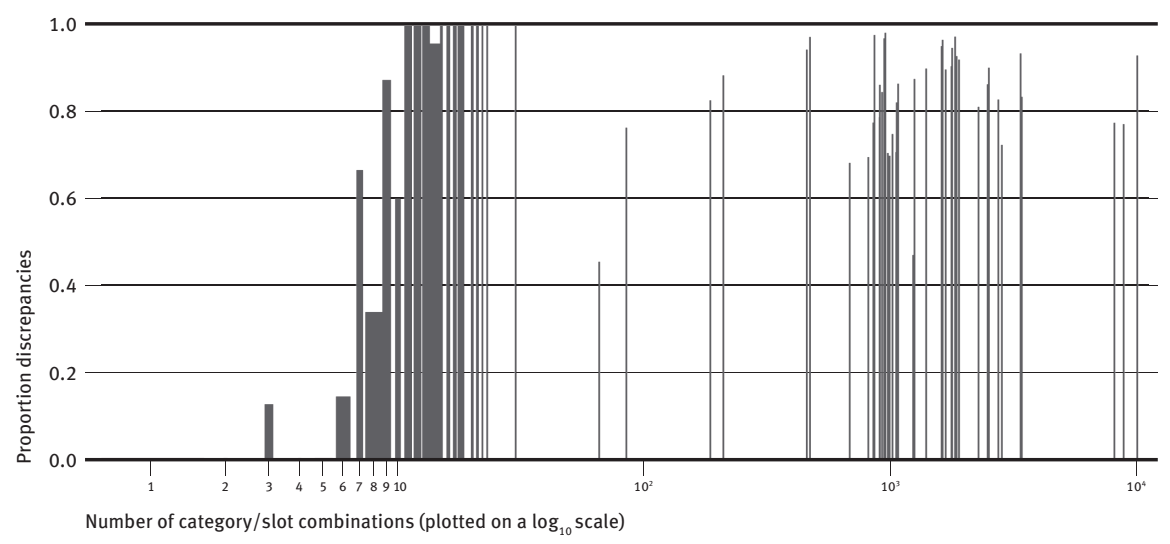

Figure 2. Proportion of alignment discrepancies in overt agreement morphology vs. agreement trigger potentials ( $y$-axis) in correlation with the number of category/slot combinations defined per agreement system ( $x$-axis, plotted on a $\log _{10}$ scale). Barwidth is proportional to the count of systems (from the total of $N=289$ ) within each given number of category/slot combinations.

It is not immediately clear why languages exploit the opportunity space for discrepancies so strongly. One possibility is that complex morphological systems may have developed through repeated accretion of freshly grammaticalized markers, each giving rise to new alignment patterns somewhere in the system. For example, if a language develops $\mathrm{P}$ agreement based on accusatively-marked pronouns, one expects the morphology to keep the emerging agreement markers separate and in a different position from older agreement markers. The result would be neutral alignment in terms of trigger potentials, but $S=A \neq P$ alignment in the morphological structure for this position. This is a plausible scenario and can be observed, for example, throughout Romance. The question whether this is a universally valid scenario, however, must be left for detailed research on the extent to which agreement systems reflect layered grammaticalization of casemarked pronouns. For now, we conclude that richer paradigms lead to more discrepancies and that 7 categories represent the critical threshold for this. 


\section{Implications for typological generalizations}

Another question that arise from our findings concerns the kinds of alignment where discrepancies are concentrated. Table 2 gives an overview of the distribution of alignments types in overt Morphological Marking and among Trigger Potentials, excluding again non-tripartite alignment. The strongest deviation, alone accounting for $51 \%$ of the total $\chi^{2}$-deviation (284.41), comes from the increased proportion of neutral alignments among agreement Trigger Potentials (with $41 \%$ as compared to $14 \%$ in the morphology). While these discrepancies are not logically necessary, they reflect the widespread pattern in agreement systems illustrated by the Tirmaga, Pipil and Ch'orti' examples above: although there is agreement morphology for all three arguments, the morphology makes distinctions, mostly aligning A with S.

Table 2. Proportion of alignments in overt morphology compared to trigger potentials, excluding tripartite alignment $(N=289)$

\begin{tabular}{lcccc}
\hline & S=A=P & S=A $\neq \mathbf{P}$ & S=P $\neq \mathbf{A}$ & S $\neq \mathbf{A}=\mathbf{P}$ \\
\hline Morphological Marking & 0.14 & 0.37 & 0.21 & 0.28 \\
Trigger Potential & 0.41 & 0.55 & 0.03 & 0.01 \\
\hline
\end{tabular}

The flip side of this is a heavily increased proportion of ergative and $\mathrm{S} \neq \mathrm{A}=\mathrm{P}$ alignments in Morphological Marking (together 49\% vs. 4\% in Trigger Potentials). This could potentially challenge the relatively well-established principle that verb agreement is strongly biased against $\mathrm{S} \neq \mathrm{A}$ alignment patterns (e.g. Siewierska 2004). Given the discrepancies we noted above, it is possible that such an antiergative bias only holds for relatively simple agreement systems where discrepancies are more limited (cf. Figure 2).

Figure 3 appears to confirm this suspicion since more complex systems (to the right on the graph) indeed tend to have a lower proportion of $\mathrm{S}=\mathrm{A}(=\mathrm{P})$ alignments, i.e. more $S \neq A$ patterns. Decreased $S=A(=P)$ proportions are less common among simpler systems (to the left of the graph), where the only notable exception consists of a few radically ergative systems with one single agreement category (e.g. gender agreement in Nakh-Daghestanian, represented here by 5 systems $^{9}$ ).

9 The only other cases in our database are ergative agreement in Nias (Austronesian) and in Hurrian, and S-only agreement in Tuvaluan (Austronesian), which results in $\mathrm{S} \neq \mathrm{A}=\mathrm{P}$ alignment. 


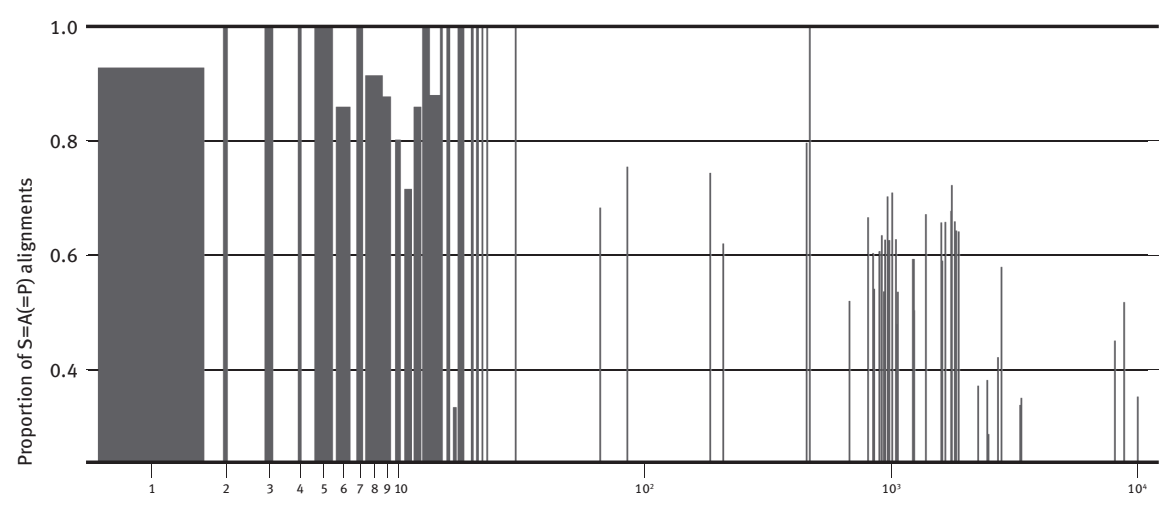

Number of category/slot combinations (plotted on a $\log _{10}$ scale)

Figure 3. Proportion of $\mathrm{S}=\mathrm{A}(=\mathrm{P})$ alignments in overt agreement morphology ( $\mathrm{y}$-axis) in correlation with the number of category/slot combinations defined per agreement system ( $x$-axis, plotted on a $\log _{10}$ scale). Barwidth is proportional to the count of systems (from the total of $N=289$ ) within each given number of category/slot combinations.

However, as shown by the thin bar widths on the righthand side of Figure 3, more complex systems are much rarer than simpler systems (at least in our database, but we believe this to be fairly representative of worldwide distributions). Also, they tend to be concentrated only in a few families: in our database of 289 systems, there are only 4 families (Algonquian, Nilotic, Tacanan and the Kiranti group of Sino-Tibetan) and the family-level isolate Ainu which contain at least one system that is complex in the sense that it contains at least 60 category/slot combinations. ${ }^{10}$ When one surveys the proportions of $\mathrm{S}=\mathrm{A}(=\mathrm{P})$ alignments in these systems (see the Appendix for a complete list), one notices that they hardly ever fall below $50 \%$. This reflects a general trend, also found in families with members showing moderate complexity: Table 3 lists the mean proportions of $\mathrm{S}=\mathrm{A}(=\mathrm{P})$ (and if applicable, standard deviations) for all families where this mean is below 1 . There are only seven further families that have mean proportions of $\mathrm{S}=\mathrm{A}(=\mathrm{P})$ below or equal 0.5, i.e. families that show a possible trend favoring ergative alignments. Nakh-Daghestanian and Algonquian are the only families in the table where this trend is relatively compact and suggestive of a family-wide feature. The other families in Table 3with mean proportions below or equal 0.5 either show large standard deviations (Mayan, Macro-Ge) or are represented only by single members (Hurrian, Zuni, Muskogean).

1060 is a reasonable threshold for calling a system 'complex' because there is a natural gap in Figure 3 between systems up to 30 and systems with more than 60 categories/slot combinations. 
Table 3. Mean proportions $\mu$ of $\mathrm{S}=\mathrm{A}(=\mathrm{P})$ in overt morphology below 1 in families, ordered by proportions. $N$ (cat. comb) shows the range of number of category/slot combinations across all members of the family in our database

\begin{tabular}{lrrrr}
\hline Family & $N$ (systems) & $N$ (cat./slot comb.) & $\mu$ & std. dev. \\
\hline Hurrian & 1 & 1 & 0.00 & \\
Nakh-Daghestanian & 5 & $(1,1)$ & 0.00 & 0.00 \\
Zuni & 1 & 6 & 0.00 & \\
Mayan & 11 & $(8,17)$ & 0.39 & 0.49 \\
Algonquian & 10 & $(2266,10047)$ & 0.40 & 0.09 \\
Macro-Ge & 2 & $(4,6)$ & 0.50 & 0.71 \\
Muskogean & 1 & 8 & 0.50 & \\
Kiranti & 29 & $(457,1889)$ & 0.63 & 0.10 \\
Tacanan & 1 & 66 & 0.68 & \\
Ainu & 1 & 85 & 0.75 & \\
Sepik & 5 & $(1,9)$ & 0.80 & 0.45 \\
Austronesian & 16 & $(1,14)$ & 0.81 & 0.40 \\
Nilotic & 5 & $(1,210)$ & 0.87 & 0.18 \\
Indo-European & 1 & $(1,13)$ & 0.95 & 0.22 \\
\hline
\end{tabular}

This suggests that decreased $\mathrm{S}=\mathrm{A}(=\mathrm{P})$ proportions are limited to only few families and is hardly ever a dominant trait of entire families. Given this, we expect that paradigm complexity has little impact on the universal trend towards $\mathrm{S}=\mathrm{A}$ alignment in agreement morphology, i.e. that the correlation noted in Figure 3 only reflects effects in very few languages and systems and is not a robust principle of typology. To test this hypothesis, we applied Bickel's (2011b, in press) Family Bias Method to our data. This method estimates statistical signals for diachronic biases from their expected synchronic results: if $S=A$ alignments outnumber $\mathrm{S} \neq \mathrm{A}$ alignments significantly (under binomial testing) in a family, a change towards $\mathrm{S}=\mathrm{A}$ alignments in this family was more likely than a change away from it (either because the proto-paradigm(s) showed $\mathrm{S}=\mathrm{A}$, which then hardly ever got lost, or because $\mathrm{S}=\mathrm{A}$ was not there and then it was innovated early or often in the family). If there is no significant synchronic preference, by contrast, no signal can be inferred because, in this case, there was either no diachronic bias towards a particular structure, or the difference in biases was too small to leave a signal, or the family is too young to allow a signal to show up. Using extrapolation methods, signals for diachronic biases can also be estimated for isolates and small families. ${ }^{11}$

11 The method is implemented in and available as an R package (Zakharko \& Bickel 2011). We used the method with the default settings of the package. 
In order to find out whether paradigm complexity has an effect on diachronic biases towards or against $\mathrm{S}=\mathrm{A}$ alignments in agreement morphology, families were grouped into simple (between 1 and 5 categories), moderately complex (between 6 and 30 categories or category combinations) and highly complex (above 60 categories or category combinations). The choice of cut-off points is arbitrary but it is based on the fact that 6 categories is the first point (after 1 ) at which $S=A$ proportions fall below 1.0 in Figure 3 and that, as noted earlier, there is a gap between systems with up to 30 and systems with more than 60 category combinations. ${ }^{12}$

Figure 4 summarizes the results. Almost all families are diachronically biased towards $\mathrm{S}=\mathrm{A}(=\mathrm{P})$ alignments in their agreement morphology, and this preference is observed to a comparable extent across degrees of paradigm complexity. ${ }^{13}$ The summary figure also includes the results of a separate analysis of diachronic biases in trigger potentials (rightmost bar), and the preference for $\mathrm{S}=\mathrm{A}(=\mathrm{P})$ alignment is in the same ballpark here as well. We can conclude that agreement systems strongly prefer $\mathrm{S}=\mathrm{A}(=\mathrm{P})$ alignments in both Morphological Marking and Trigger Potential. Deviations from this are limited to a few groups and languages with high (such as Algonquian) and moderate complexity (such as Mayan).

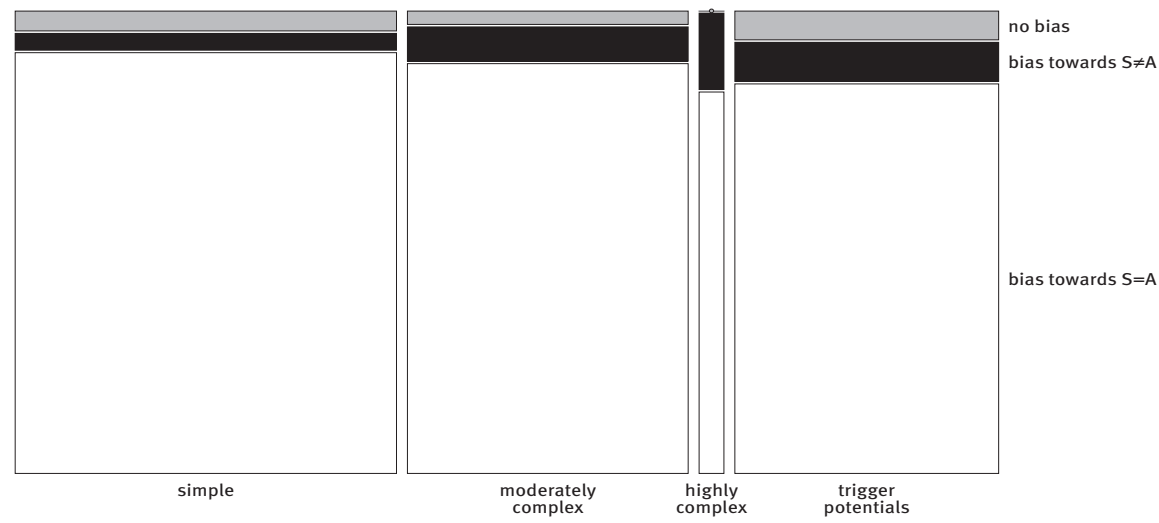

Figure 4. Proportion of estimated diachronic family biases towards $S=A(=P)$ vs. $S \neq A$ alignments in Morphological Marking across different degrees of paradigm complexity, and among agreement Trigger Potentials. Tile sizes are proportional to frequencies (Meyer et al. 2009); a small circle indicates zero counts.

12 When families were diverse with regard to these categories of complexity (e.g. Indo-European or Austronesian, cf. the range of category counts in Table 3), we split the family into smaller groups that fell consistently into one or the other group. Whenever possible, such groups were based on known genealogical subgroups, as defined in Nichols \& Bickel (2009).

13 A likehood ratio $\chi^{2}$ test comparing a loglinear model with vs. without an interaction between bias direction $\mathrm{x}$ complexity type suggests independence: $\chi_{\Delta}^{2}=2.29, d f=2, \mathrm{p}=.32$. 


\section{Conclusion}

Siewierska (2003) raised an important issue for typologies of alignment. Looking at alignment patterns in agreement systems in terms of the type of roles that can trigger agreement in the syntax (i.e. Trigger Potential) leads to very different characterizations than when one examines alignment patterns for specific agreement markers in specific morphological positions (i.e. Morphological Marking). Discrepancies are in fact severe, and it is imperative that typology carefully distinguish between different notions of alignment in agreement systems. Some of the sources of these discrepancies are trivial and have to do with the logic of determining alignments. However, we also observed (Section 4) that a substantial proportion of discrepancies is empirical in nature: agreement morphology could in principle be more in line with agreement syntax. At present it is not clear to us why morphological systems should exploit the possibility for discrepancies as strongly as they do, but we suspect that this has to do with the complex histories of grammaticalizing layer after layer in agreement systems. Such a scenario would explain why discrepancies become stronger the more complex paradigms are in terms of the number of referential categories and category combinations they are sensitive to.

While the study of discrepancies that Siewierska called for gives new insights into possible historical scenarios on how alignment patterns have developed in agreement systems, it could in principle challenge received universal principles on preferred alignments in such systems. As we showed in Section 5, however, confounding effects are severely limited: there are only very few language families in the world where there seems to have been a bias away from $\mathrm{S}=\mathrm{A}$ and towards $\mathrm{S} \neq \mathrm{A}$ alignments, and this is true regardless of whether one looks at agreement syntax or agreement morphology. There is a slight preference for $\mathrm{S} \neq \mathrm{A}$ alignments in more complex paradigms, but it is only in a handful of language families that this is a significant and diachronically relevant trend (e.g. in Algonquian). In all other families, there is a very strong overall bias towards $\mathrm{S}=\mathrm{A}$, even when paradigms are exceedingly complex, as, for instance, in Kiranti.

\section{Abbreviations}

1 first person, 2 second person, 3 third person, ACC accusative, $\mathrm{F}$ feminine, IND indicative, INDEP independent indicative, $M$ masculine, NOM nominative, NSNPST non-simple non-past, PRS present, PST past, PL plural, SG singular, SNPST simple non-past. 


\section{Appendix}

Proportion of $\mathrm{S}=\mathrm{A}(=\mathrm{P})$ in overt morphology and number of category/slot combinations per system in families where at least one system has more than 60 combinations

\begin{tabular}{|c|c|c|c|c|}
\hline Family & Language & System & $\operatorname{Pr}(\mathbf{S}=\mathbf{A})$ & $N$ (category/slot comb.) \\
\hline Ainu & Ainu & & 0.753 & 85 \\
\hline Algonquian & Arapaho & INDEP & 0.287 & 2495 \\
\hline Algonquian & Atikamekw & INDEP.NPST & 0.450 & 8117 \\
\hline Algonquian & Blackfoot & INDEP & 0.578 & 2817 \\
\hline Algonquian & Cheyenne & INDEP.PRS.IND & 0.338 & 3354 \\
\hline Algonquian & Cree (Plains) & INDEP & 0.517 & 8845 \\
\hline Algonquian & Menomini & INDEP & 0.372 & 2266 \\
\hline Algonquian & Micmac & INDEP.IND & 0.353 & 10047 \\
\hline Algonquian & Munsee & INDEP.NPST & 0.381 & 2467 \\
\hline Algonquian & Ojibwa (Eastern) & INDEP.PRS & 0.350 & 3391 \\
\hline Algonquian & Passamaquoddy & INDEP.PRS & 0.421 & 2726 \\
\hline Kiranti & Athpare & IND & 0.676 & 1761 \\
\hline Kiranti & Bahing & NPST.IND & 0.626 & 951 \\
\hline Kiranti & Bahing & PST.IND & 0.540 & 859 \\
\hline Kiranti & Bantawa & IND & 0.589 & 1621 \\
\hline Kiranti & Belhare & IND & 0.721 & 1772 \\
\hline Kiranti & Camling & IND & 0.503 & 1247 \\
\hline Kiranti & Chintang & NPST.IND & 0.658 & 1822 \\
\hline Kiranti & Dumi & NPST.IND & 0.479 & 1057 \\
\hline Kiranti & Hayu & NPST.IND & 0.519 & 682 \\
\hline Kiranti & Hayu & PST.IND & 0.665 & 811 \\
\hline Kiranti & Jero & IND & 0.536 & 941 \\
\hline Kiranti & Koyi & NPST.IND & 0.602 & 850 \\
\hline Kiranti & Koyi & PST.IND & 0.605 & 901 \\
\hline Kiranti & Kulung & NPST.IND & 0.633 & 922 \\
\hline Kiranti & Kulung & PST.IND & 0.606 & 903 \\
\hline Kiranti & Kõic & NPST.IND & 1.000 & 471 \\
\hline Kiranti & Kõic & PST.IND & 0.794 & 457 \\
\hline Kiranti & Limbu & NPST.IND & 0.640 & 1889 \\
\hline Kiranti & Limbu & PST.IND & 0.642 & 1847 \\
\hline Kiranti & Lohorung & NPST.IND & 0.592 & 1238 \\
\hline Kiranti & Lohorung & PST.IND & 0.592 & 1238 \\
\hline Kiranti & Old Thulung (Mukli) & NPST.IND & 0.626 & 1052 \\
\hline Kiranti & Old Thulung (Mukli) & PST.IND & 0.625 & 989 \\
\hline Kiranti & Puma & NPST.IND & 0.656 & 1668 \\
\hline
\end{tabular}




\begin{tabular}{lllrr}
\hline Family & Language & System & $\operatorname{Pr}(\mathbf{S}=\mathbf{A})$ & $N$ (category/slot comb.) \\
\hline Kiranti & Thulung (Mukli) & NPST & 0.708 & 1016 \\
Kiranti & Thulung (Mukli) & PST & 0.701 & 973 \\
Kiranti & Wambule & IND & 0.535 & 1071 \\
Kiranti & Yakkha & IND & 0.656 & 1606 \\
Kiranti & Yamphu & IND & 0.670 & 1391 \\
Nilotic & Nandi & NSNPST & 1.000 & 10 \\
Nilotic & Nandi & SNPST & 1.000 & 8 \\
Nilotic & Teso & & 0.742 & 186 \\
Nilotic & Turkana & & 0.619 & 210 \\
Tacanan & Reyesano & & 0.682 & 66 \\
\hline
\end{tabular}

\section{References}

Bickel, Balthasar. 2011a. Grammatical relations typology. In Jae Jung Song (ed.), The Oxford Handbook of Language Typology, Oxford: Oxford University Press.

Bickel, Balthasar. 2011b. Statistical modeling of language universals. Linguistic Typology 15. 401-414.

Bickel, Balthasar. in press. Distributional biases in language families. In Balthasar Bickel, Lenore A. Grenoble, David A. Peterson \& Alan Timberlake (eds.), Language typology and historical contingency: studies in honor of Johanna Nichols, Amsterdam: Benjamins (pre-print available at http://www.spw.uzh.ch/bickel-files/papers/stability.fsjn.2011 bickelrevised.pdf).

Bickel, Balthasar \& Johanna Nichols. 2007. Inflectional morphology. In Timothy Shopen (ed.), Language typology and syntactic description, 169-240. Cambridge: Cambridge University Press (Revised second edition).

Bickel, Balthasar \& Johanna Nichols. 2009. Case marking and alignment. In Andrej Malchukov \& Andrew Spencer (eds.), The Oxford Handbook of Case, 304-321. Oxford: Oxford University Press.

Bickel, Balthasar, Manoj Rai, Netra Paudyal, Goma Banjade, Toya Nath Bhatta, Martin Gaenszle, Elena Lieven, Iccha Purna Rai, Novel K. Rai \& Sabine Stoll. 2010. Ditransitives and threeargument verbs in Chintang and Belhare (Southeastern Kiranti). In Andrej Malchukov, Martin Haspelmath \& Bernard Comrie (eds.), Studies in Ditransitive Constructions. A Comparative Handbook, 382-408. Berlin \& New York: De Gruyter Mouton.

Bryant, Michael Grayson. 1999. Aspects of Tirmaga grammar. University of Texas at Arlington dissertation.

Campbell, Lyle. 1985. The Pipil language of El Salvador. Berlin \& New York: De Gruyter Mouton. Dahlstrom, Amy. 1991. Plains Cree Morphosyntax. Garland Publishing.

Holst, Jan Henrik. 2001. Lettische Grammatik. Hamburg: Helmut Buske Verlag.

Mathiassen, Terje. 1997. A Short Grammar of Latvian. Columbus, Ohio: Slavica Publishers.

Meyer, David, Achim Zeileis \& Kurt Hornik. 2009. vcd: visualizing categorical data. R package (http://www.R-project.org). 
Nau, Nicole. 1998. Latvian, vol. 217 Languages of the World/Materials. München: Lincom Europa. Nichols, Johanna \& Balthasar Bickel. 2009. The AUTOTYP genealogy and geography database: 2009 release. Electronic database, http://www.uzh.ch/spw/autotyp.

Opgenort, J. R. 2005. A Grammar of Jero, vol. 5/3 Brill's Tibetan Studies Library: Languages of the Greater Himalayn Region. Leiden: E. J. Brill.

Quizar, Robin. 1994. Motion verbs in Ch'orti'. Función 15-16.

R Development Core Team. 2012. R: a language and environment for statistical computing. Vienna: R Foundation for Statistical Computing, http://www.r-project.org.

Sarkar, Deepayan. 2010. lattice : Lattice Graphics. R package version 0.18-8. http://CRAN.R-project.org/package=lattice.

Siewierska, Anna. 2003. Person agreement and the determination of alignment. Transactions of the Philological Society 101. 339-370.

Siewierska, Anna. 2004. Person. Cambridge: Cambridge University Press.

Witzlack-Makarevich, Alena. 2011. Typological variations in grammatical Relations. University of Leipzig dissertation.

Witzlack-Makarevich, Alena, Lennart Bierkandt, Taras Zakharko \& Balthasar Bickel. 2011. Decomposing hierarchical alignment: participant scenarios as conditions on alignment. 44th Annual Meeting of the Societas Linguistica Europaea, Logroño, September 8.

Zakharko, Taras \& Balthasar Bickel. 2011. familybias: Family bias estimation. R package, http://www.spw.uzh.ch/software.html. 